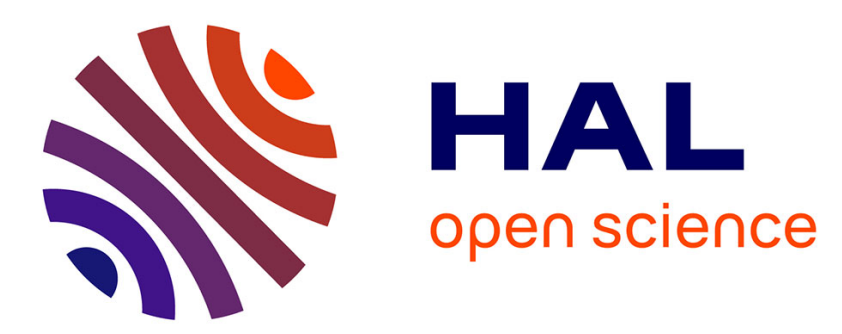

\title{
Estimation de la valeur fertilisante azotée du lisier par simulation numérique
}

Manh Le Pham, Raymond Lambert, Henri Laudelout

\section{To cite this version:}

Manh Le Pham, Raymond Lambert, Henri Laudelout. Estimation de la valeur fertilisante azotée du lisier par simulation numérique. Agronomie, 1984, 4 (1), pp.63-74. hal-00884612

\section{HAL Id: hal-00884612 \\ https://hal.science/hal-00884612}

Submitted on 1 Jan 1984

HAL is a multi-disciplinary open access archive for the deposit and dissemination of scientific research documents, whether they are published or not. The documents may come from teaching and research institutions in France or abroad, or from public or private research centers.
L'archive ouverte pluridisciplinaire HAL, est destinée au dépôt et à la diffusion de documents scientifiques de niveau recherche, publiés ou non, émanant des établissements d'enseignement et de recherche français ou étrangers, des laboratoires publics ou privés. 


\title{
Estimation de la valeur fertilisante azotée du lisier par simulation numérique
}

\author{
Manh Le PHAM, Raymond LAMBERT \& Henri LAUDELOUT \\ Département des Sciences du Sol, Faculté des Sciences Agronomiques, Université catholique de Louvain, place
} Croix du Sud, 2, B 1348 Louvain-la-Neuve

RÉSUMÉ

\begin{abstract}
Un sol a été incubé avec du lisier ou du sulfate d'ammonium à des doses variables et à différentes températures.

On a obtenu des résultats expérimentaux relatifs à l'oxydation de l'azote ammoniacal, à la production de l'azote nitrique, à la variation du $\mathrm{pH}$ du sol et à la densité de la population bactérienne par la numération sur milieu gélosé, confirmée par des vérifications de la teneur en ATP du sol et par la numération microscopique directe.

La quantité de l'azote organique minéralisable dans les conditions de laboratoire (humidité et température constante) est estimée en utilisant un modèle où le seul paramètre arbitrairement ajusté aux résultats expérimentaux est cette dernière quantité.
\end{abstract}

Mots clés additionnels : Matière organique, nitrification, minéralisation, modèle mathématique, pH, pouvoir tampon du sol.

\begin{abstract}
Effluent was incubated with soil with variation in the amount of effluent, ammonium sulfate added, and temperature. Experimental results were obtained on ammonium-nitrogen oxidation, nitrate-nitrogen production, bacterial plate count and $\mathrm{pH}$, with checks on bacterial density made by the bioluminescence technique and microscopic total count. The amount of organic nitrogen mineralizable under laboratory incubation conditions (constant soil moisture and temperature) was estimated by using a model where it was the only parameter arbitrarily adjusted to the experimental results.
\end{abstract}

Additional key words : Organic matter, nitrification, mineralization, mathematical modelling, pH, soil buffer capacity.

\section{INTRODUCTION}

La composition chimique du lisier est extrêmement variable, même lorsqu'il provient d'une seule espèce animale. On peut toutefois admettre qu'il apporte de 3 à $8 \mathrm{~kg}$ d'azote par $\mathrm{m}^{3}$ dont un tiers à la moitié sont de nature organique, le reste étant présent sous forme d'azote ammoniacal.

Il n'y a guère de doute en ce qui concerne la valeur fertilisante de l'azote ammoniacal du lisier. On peut toutefois se demander si l'azote organique subit une minéralisation suffisamment rapide pour que sa contribution à la nutrition azotée de la plante soit appréciable. D'autre part, les effets favorables éventuels de la matière organique du lisier sur la structure du sol sont également liés à sa capacité de décomposition. Si celle-ci est trop faible, il est certain que l'épandage continu du lisier, surtout s'il est pratiqué sans incorporation dans la couche arable comme c'est le cas pour les prairies permanentes, peut conduire à une diminution de la capacité de régénération du tapis herbacé.

Certaines observations obtenues par LECOMTE et al. (1979) semblent montrer que, dans les conditions de climat et de sol du Nord de la France et de la Wallonie, non seulement l'assimilabilité de l'azote organique du lisier est réduite, mais encore que cette matière organique exerce un effet dépressif sur l'azote ammoniacal qui l'accompagne.

Les recherches sur les phénomènes microbiologiques associés à l'incorporation de lisier au sol ou à son épandage en surface ont été en grande partie limitées aux bactéries pathogènes. Des autres études effectuées, il semble toutefois se dégager une relative inertie biologique du lisier (EILAND, 1981). Cette inertie n'apparaît pas ici liée à une inhibition des processus de décomposition par les métaux lourds, notamment $\mathrm{Cu}$ (tabl. 1), que des doses importantes de lisier peuvent parfois apporter.

Nous avons donc procédé à une série d'observations sur la 
densité de la population microbienne du lisier ou de sols auxquels du lisier était incorporé à dose variable, sur la cinétique de la nitrification de l'azote ammoniacal apporté au sol et sur l'activité respiratoire du sol.

L'ensemble des résultats de ces déterminations a été confronté avec les résultats d'un modèle mathématique dont les éléments ont été décrits dans des publications antérieures (LAUDELOUT et al., 1974, 1976, 1977 ; LAUDELOUT \& LAMBERT, 1982).

Le but de ces essais de simulation est d'arriver à une estimation de la fraction de la matière organique du lisier qui serait susceptible d'une minéralisation avec une constante de temps égale ou inférieure au mois et, par conséquent, présenterait un intérêt agronomique certain, particulièrement comme fertilisant au printemps.

\section{TECHNIQUES EXPÉRIMENTALES ET MATÉ- RIEL UTILISÉ}

Le sol et le lisier utilisés présentent les caractéristiques citées dans le tableau 1.

\section{TABLEAU 1}

Caractéristiques áu lisier (sur matière fraiche) et du sol (sur fraction fine) employés.

Effluent (pig slurry) and soil composition.

\begin{tabular}{|c|c|c|}
\hline & $\begin{array}{l}\text { Lisier } \\
\text { de porc }\end{array}$ & Sol \\
\hline & & $\begin{array}{l}\text { Limon nivéo-ćolien } \\
\text { horizon Ap }(0-20 \mathrm{~cm}) \\
\text { de Gembloux }\end{array}$ \\
\hline $\mathrm{pH}$ & 7,5 & 6,1 \\
\hline N-total & $6,64 \%$ & $1,7 \%$ \\
\hline $\mathrm{NH}_{4}^{+}-\mathrm{N}$ & $4,52 \%$ & 42 p.p.m. \\
\hline $\mathrm{NO}_{3}^{-}-\mathrm{N}$ & $0,14 \%$ & 22 p.p.m. \\
\hline Matière sèche & $4,3 \%$ & L \\
\hline $\mathrm{Cu}$ & $43 \mathrm{mg} / 1$ & - \\
\hline $\mathrm{C} / \mathrm{N}$ & 10 & 6,95 \\
\hline $\mathrm{CEC}$ & - & $10 \mathrm{meq} / 100 \mathrm{~g}$ \\
\hline
\end{tabular}

\section{A. Mesures du laboratoire}

\section{Expérience d'incubation}

Le sol est séché à la température ambiante, broyé et tamisé à $2 \mathrm{~mm}$.

Des fractions de $10 \mathrm{~g}$ de sol contenant 5 et 15 p. 100 de lisier frais ou bien 225 et 675 p.p.m. d'azote ammoniacal (sous forme de $\left(\mathrm{NH}_{4}\right)_{2} \mathrm{SO}_{4}$ ) sont humectées à une humidité de 40 p. 100 , correspondant à la capacité au champ de ce sol remanié. Ces fractions sont incubées à l'obscurité à 5, 13, 25 et $30^{\circ} \mathrm{C}$, en atmosphère humide, de telle façon que la variation de la teneur en eau reste inférieure à $1 \mathrm{p} .100$ à la fin de l'expérience. Le risque de perturber les phénomènes étudiés lors du prélèvement des échantillons sur une masse plus importante de sol nous a fait écarter la technique de l'aliquote et nous avons choisi, pour la quantité de lisier incorporé au sol, les doses habituellement étudiées (COOPER, 1975). Notons que la dose simple de lisier représente le double du traitement fort employé à Gembloux (LECOMTE et al., 1979) mais la dose triple reste inférieure au traitement minimal appliqué au Texas (SMITH et al., 1980).
Après incubation pendant un nombre de jours variant de 1 à 50 , on ajoute à l'échantillon $95 \mathrm{ml}$ d'eau stérile contenant des billes de verre de $2 \mathrm{~mm}$. On agite mécaniquement pendant $10 \mathrm{mn}$ (CLARK, 1965).

Sur la suspension obtenue, on a procédé aux déterminations suivantes :

\section{a) Numération des bactéries viables par culture (CLARK, 1965)}

Chaque dilution est ensemencée en 5 répétitions. On a utilisé le milieu gélosé de THORNTON (1922) incubé pendant $7 \mathrm{j}$ à $25^{\circ} \mathrm{C}$.

\section{b) Numération directe}

$1 \mathrm{ml}$ de la suspension de sol est dilué dans $9 \mathrm{ml}$ de gélose à 0,1 p. 100 stérile, refroidie à $45^{\circ} \mathrm{C}$. La préparation est réalisée sur un hémocytomètre suivant la technique de JONES \& MOLLISON (1948). Le film formé est récolté sur une lame porte-objet et seules les cellules bactériennes sont comptées.

\section{c) Détermination de la teneur en ATP par biolumines- cence}

L'extraction de l'AtP est faite avec le réactif NRB de LUMAC (1978). Les mesures sont réalisées dans un appareil Celltester Modèle 1030 de LuMAC avec un réactif composé du mélange brut de luciférine et luciférase.

La concentration de l'échantillon en ATP est déterminée par étalonnage interne.

\section{d) Détermination de $\mathrm{NH}_{4}^{+}$et $\mathrm{NO}_{3}^{-} \mathrm{N}$}

Ces déterminations sont effectuées avec des électrodes spécifiques Modèle ORION 95-10 et 93-07, après extraction de $10 \mathrm{~g}$ de sol par $90 \mathrm{ml}$ de solution $0.5 \mathrm{M}_{\text {de }} \mathrm{K}_{2} \mathrm{SO}_{4}$. Les résultats des déterminations proviennent de la moyenne de 3 échantillons prélevés.

Une étude préliminaire de 6 semaines à ces 4 températures sur les échantillons de sol et de sol additionné de lisier a montré que le nombre de micromycètes déterminé par le milieu de MARTIN (1950) est de plusieurs ordres de grandeur inférieur à celui des bactéries $\left(10^{5} / \mathrm{g}\right.$ de sol par rapport à $10^{3} / \mathrm{g}$ sol). Nous nous limitons par la suite à suivre la variation de la biomasse par celle des bactéries.

\section{Numération des bactéries anaérobies du lisier}

Les numérations sont effectuées sur le milieu de Kurihara (HOBSON, 1969), le liquide de rumen étant remplacé par du lisier centrifugé.

L'incubation est réalisée à $30^{\circ} \mathrm{C}$, pendant $48 \mathrm{~h}$, dans une enceinte anaérobique Gaspak 150 de BBL.

\section{B. Simulation sur ordinateur}

Le programme de calcul utilisé s'inspire des méthodes publiées antérieurement par ce laboratoire.

Rappelons brièvement qu'il consiste dans la solution numérique de 8 équations différentielles dont 2 se rapportent à la croissance des bactéries de la nitrification, 3 à l'oxydation de l'ammonium et du nitrite ou à la production du nitrate, 2 à la croissance de la biomasse et à son action sur la décomposition de l'azote organique et la dernière, à la production d'ion $\mathrm{H}^{+}$parallèlement à l'oxydation biologique de l'ammonium (annexe 1).

L'effet de la variation du $\mathrm{pH}$ sur la cinétique de la nitrification est calculé comme nous l'avons montré dans un 
travail antérieur (LAUDELOUT et al., 1976). Pour des raisons évidentes, seule la branche acide de la courbe $\mathrm{du} \mathrm{pH}$ a été utilisée.

Les données expérimentales sur le pouvoir tampon du sol nécessaires au calcul de l'effet de l'oxydation de l'ammonium sur son $\mathrm{pH}$ ont été obtenues de la façon suivante :

Une quantité fixe d'eau $(50 \mathrm{ml})$ contenant une quantité connue en ions $\mathrm{H}^{+}$est agitée avec des quantités de sol sec variant de 20 à $50 \mathrm{~g}$; le pH de la suspension est mesuré jusqu'à ce qu'une stabilisation relative soit observée après $72 \mathrm{~h}$ environ.

La représentation du $\mathrm{pH}$ (fig. 1), mesuré après stabilisation en fonction de la quantité d'eau présente par $\mathrm{g}$ de sol, montre que la variation du $\mathrm{pH}$ en fonction du rapport eau/sol est suffisamment linéaire (coefficient de corrélation linéaire supérieure à $\pm 92 \mathrm{p}$. 100) pour que l'on puisse extrapoler les valeurs du $\mathrm{pH}$ à celle qui correspondrait à la teneur en eau du sol pendant l'expérience de minéralisation et de nitrification.

Des expériences identiques sont répétées, à la seule différence que les quantités d'eau ajoutée contiennent une quantité fixe d'acide sulfurique allant de 0 à $100 \mathrm{meq}$ d'ions $\mathrm{H}^{+}$par litre de solution.

L'extrapolation se fait, dans le modèle, pour la teneur en eau présente dans le sol et une intrapolation s'effectue pour la quantité calculée d'ions $\mathrm{H}^{+}$produits par la nitrification entre 2 des points de la courbe tampon.

Ce programme, rédigé en BASIC APPLESOFT et en ForTRAN 77, est disponible sur demande; le temps moyen d'exécution pour une simulation de $50 \mathrm{j}$ sur APPLE II est de $2 \mathrm{~h}$; la forme compilée du programme ne demande que $40 \mathrm{mn}$.

\section{RÉSULTATS}

\section{A. Estimation de la biomasse}

Les premières données que l'on pouvait obtenir sur l'activité biologique du lisier avaient trait à la valeur de la biomasse bactérienne qu'il entretient à l'état stationnaire.

Le tableau 2 montre le nombre de germes obtenus en culture aérobie, anaérobie, par bioluminescence et par microscopie directe.

\section{TABLEAU 2}

Biomasse du lisier.

Effluent biomass.

Bactéries aérobies par numération sur milieu gélosé

Bactéries par numération microscopique directe

Bactéries anaérobies par numération par culture

Concentration en ATP

Rapport : nombre total de cellules/nombre viable

$1,7.10^{5} / \mathrm{ml}$

$6,6.10^{8} / \mathrm{ml}$

$6,2.10^{4} / \mathrm{ml}$

$<10^{-9} \mathrm{~g} / \mathrm{ml}$

$3,9 \times 10^{3}$

Il est intéressant de remarquer que le rapport des germes viables aux germes totaux est de l'ordre de 1 p. 1000 , c'està-dire assez nettement inférieur à ce qu'il est courant de constater dans le sol, soit de l'ordre de 1 p. 100. La validité du milieu de THORNTON est-elle en cause ? En tout cas, la valeur de ce rapport se confirme par le calcul suivant : en admettant une teneur moyenne en ATP de $10^{-15} \mathrm{~g} /$ cellule (LuMAC, 1978), on peut calculer que la biomasse est inférieure à $10^{6}$ cellules par $\mathrm{ml}$, une valeur comprise entre le nombre de bactéries viables et la valeur obtenue par numération microscopique directe mais nettement inférieure à cette dernière.

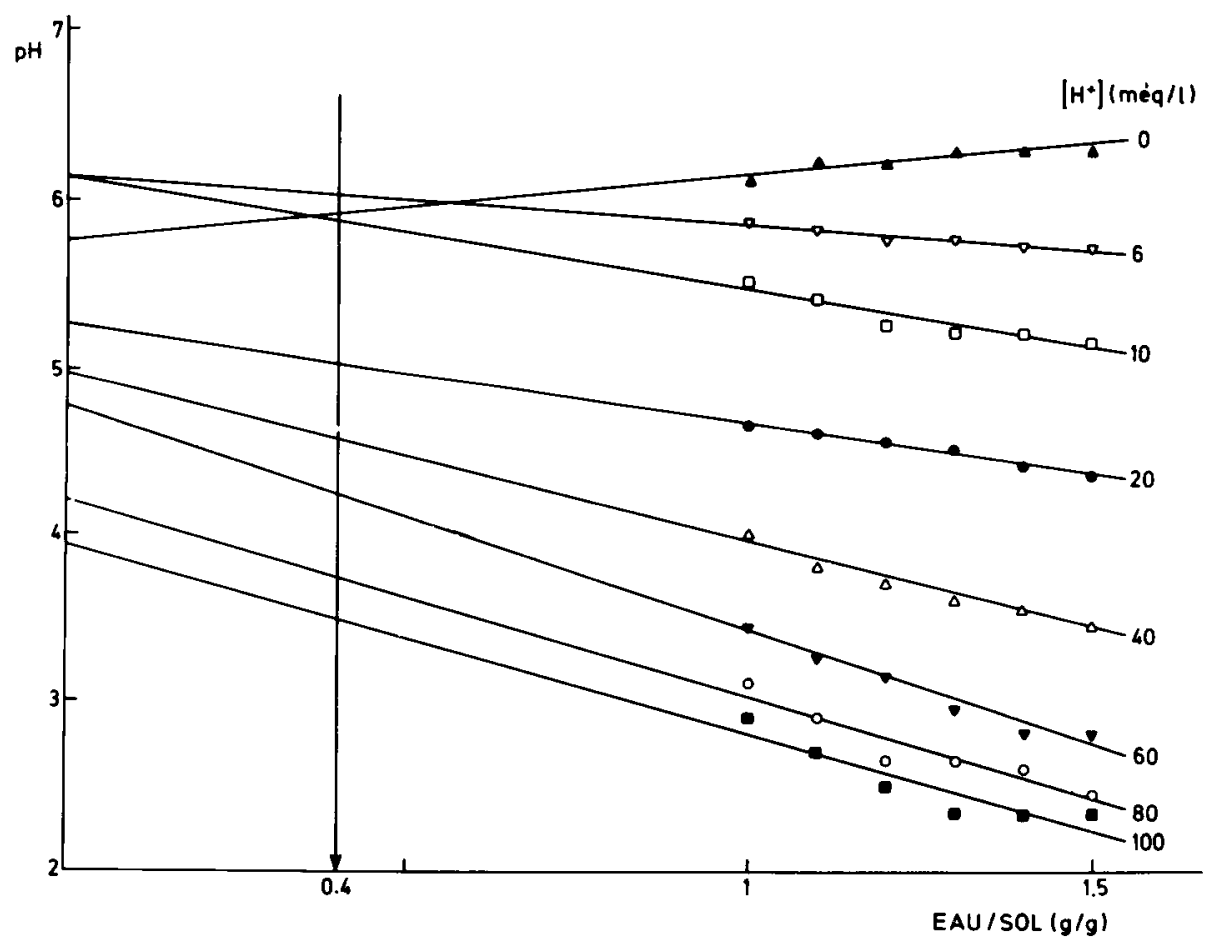

Figure 1

Evolution du pH en fonction du rapport eau-sol après stabilisation de sa valeur illustrant la technique d'extrapolation pour la détermination du pouvoir tampon à la teneur en eau utilisée pour l'incubation du sol.
Effect of water-soil ratio on soil $\mathrm{pH}$ illustrating the extrapolation technique for determining buffer capacity of soil for acid production. 
Le lisier contient donc, à côté d'une biomasse active peu importante, une quantité relativement plus importante de cellules mortes. On peut donc croire que les conditions de conservation du lisier (anaérobiose et température moyenne de l'ordre de 5 à $10^{\circ} \mathrm{C}$ ) sont telles qu'une biomasse abondante ne peut s'y développer ou s'y maintenir à l'état viable.

\section{B. Transformation du lisier dans le sol (fig. 2, 3, 4, 5 et 6)}

Les figures 2 et suivantes reproduisent, dans leur partie gauche, les données expérimentales observées à $25^{\circ} \mathrm{C}$ pour le nombre de bactéries viables exprimé soit en millions par $g$ (échelle de droite), soit en $\mu g$ d'azote par $g$ de sol (le facteur de conversion choisi étant $0,16 \mu \mathrm{g}$ d'azote par million de cellules), l'azote nitrique, l'azote ammoniacal et le $\mathrm{pH}$ lorsqu'un sol est incubé, soit tel quel (fig. 2), soit avec une dose simple de lisier ( $215 \mathrm{mg}$ de matière sèche par $100 \mathrm{~g}$ de sol, fig. 3), ou une dose triple (fig. 5), soit avec deux doses d'azote ammoniacal égales à l'azote ammoniacal apporté par chacune des 2 doses de lisier (225 et 675 p.p.m. $\mathrm{NH}_{4}-\mathrm{N}$ ) (fig. 4 et 6 ).

On remarque que :

- la biomasse augmente pendant toute la période d'incubation même avec l'échantillon témoin suite à l'humectation du sol sec, avec parfois des irrégularités marquées (fig. 5),

- l'azote ammoniacal disparaît sauf lorsque l'acidification est telle que la nitrification est arrêtée, ce qui sc passe autour de $\mathrm{pH}_{5}$ (fig. 6),
- la production de nitrate a l'allure sigmoïdale bien connue. On voit toutefois que des quantités égales d'azote ammoniacal présentes dans le lisier ou ajoutées sous la forme $\left(\mathrm{NH}_{4}\right)_{2} \mathrm{SO}_{4}$ sont oxydées suivant des cinćtiques différentes. Il va sans dire que la comparaison entre ces 2 traitements n'est pas rigoureuse puisque l'addition d'azote ammoniacal sous forme d'un sel acide ou bien en présence de la réserve alcaline contenue dans le lisier ne peut conduire à la même cinétique de nitrification étant donné l'influence du $\mathrm{pH}$ sur cette cinétique.

Dans les conditions expérimentales adoptées ici (aérobiose, $\mathrm{pH}$ du sol inférieur à 6,2) où la dénitrification et la volatilisation restent négligeables et l'immobilisation est prise en considération par le modèle, l'ensemble des données obtenues peut être utilisé pour le calcul de la teneur initiale en matière organique minéralisable apportée par le lisier et le sol. Ceci revient à ajuster le modèle de nitrification et de minéralisation aux résultats expérimentaux en manipulant ce seul paramètre par comparaisons successives de résultats de simulation plutôt que par une technique de régression non linéaire. Il va de soi que la valeur d'un modèle mathématique où l'on aurait manipulé arbitrairement plusieurs de ses paramètres serait considérablement réduite.

On trouvera au tableau 3 les valeurs des paramètres à $30^{\circ} \mathrm{C}$ et leurs caractéristiques de température utilisées dans les simulations de la partie droite des figures 2 à 6 .

Nous n'avons pas présenté sur le même graphique les courbes théoriques et les données expérimentales puisqu'il est impossible d'obtenir un parfait accord entre les valeurs

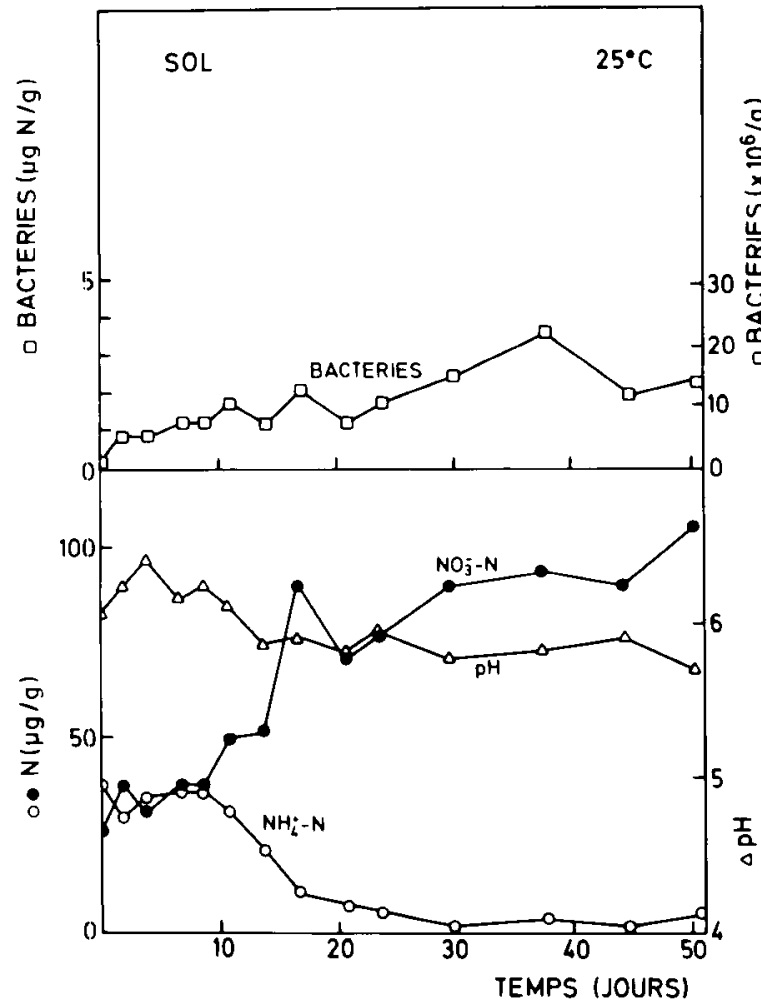

Figure 2

Evolution de la biomasse bactérienne, des teneurs en azote minéral et du $\mathrm{pH}$ dans le sol sans addition au cours d'une période d'incubation de 50 jours. A a'roite, les courbes simulées au moyen du modèle mathématique contenant les paramètres du tableau 3. Ces courbes contiennent en outre l'évolution de la teneur en matière organique (azotée minéralisable) calculée à partir des donnée expérimentales.

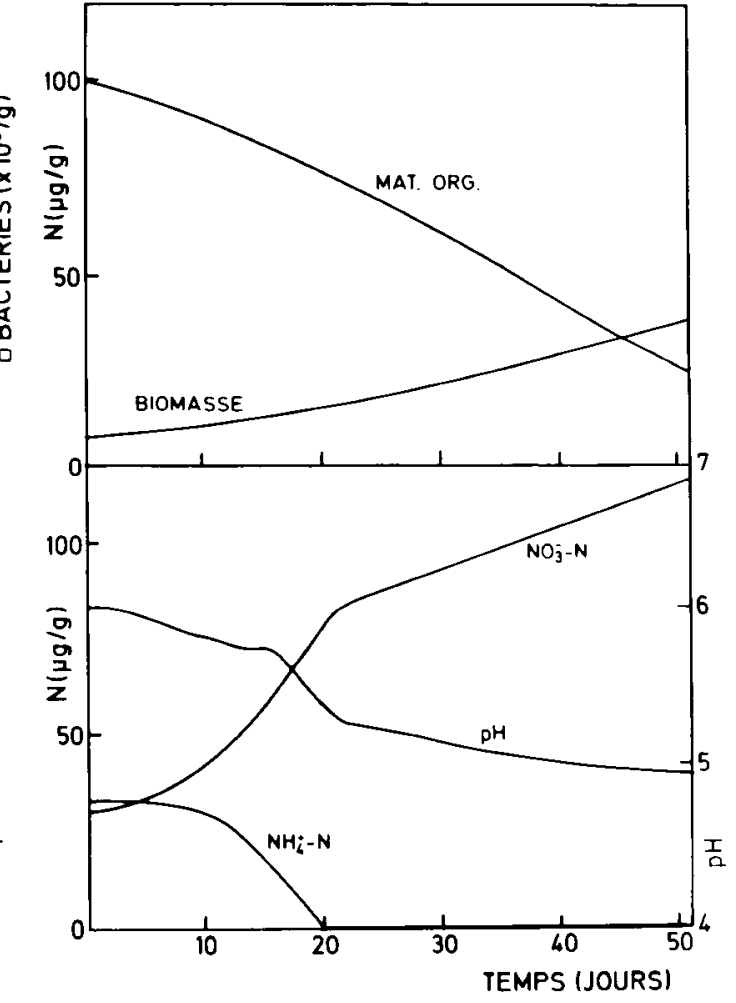

Bacterial biomass, mineral nitrogen content and $p H$ of soil samples (control) during 50 days of incubation. At right, continuous curves represent model simulations with the parameters from table 3. The mineralizable nitrogen organic matter curves is computed from experimental data. 

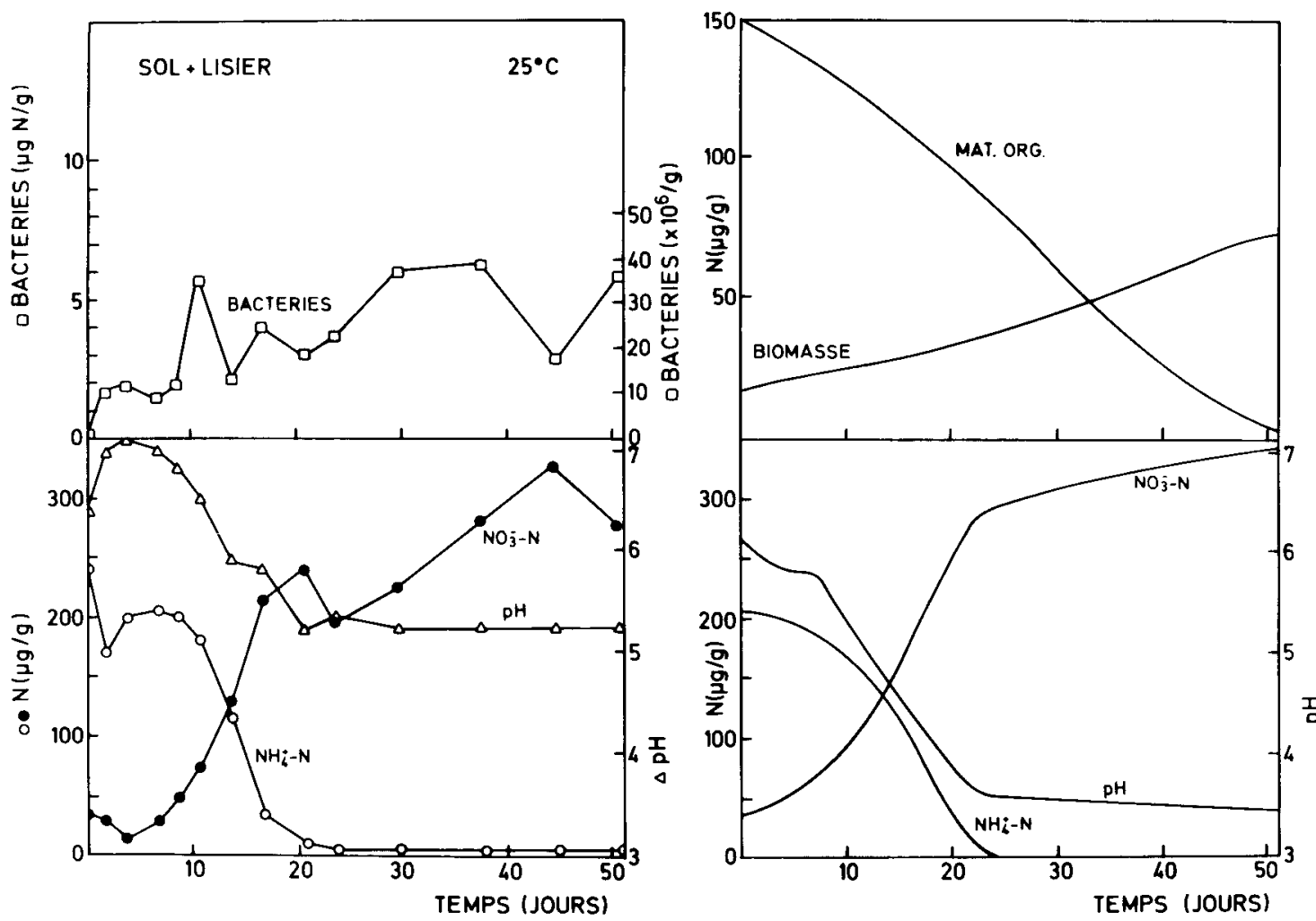

Figure 3

Le schéma expérimental est identique à celui de la figure 2, mais on a ajouté au sol 100 p.p.m. d'azote organique et 233 p.p.m. d'azote minéral sous forme de lisier. La valeur initiale en $\mathrm{NH}_{4}^{+} \mathrm{N}$ utilisée pour le calcul des courbes simulées est prise égale à la moyenne des 3 premières valeurs expérimentales.

Same experimental procedure as in fig. 2 but with 100 p.p.m. organic nitrogen and 233 p.p.m. mineral nitrogen added using pig slurry effluent. Initial value of $\mathrm{NH}_{\tilde{f}}^{+} \mathrm{N}$ for simulation represents the mean of first 3 experimental concentrations.
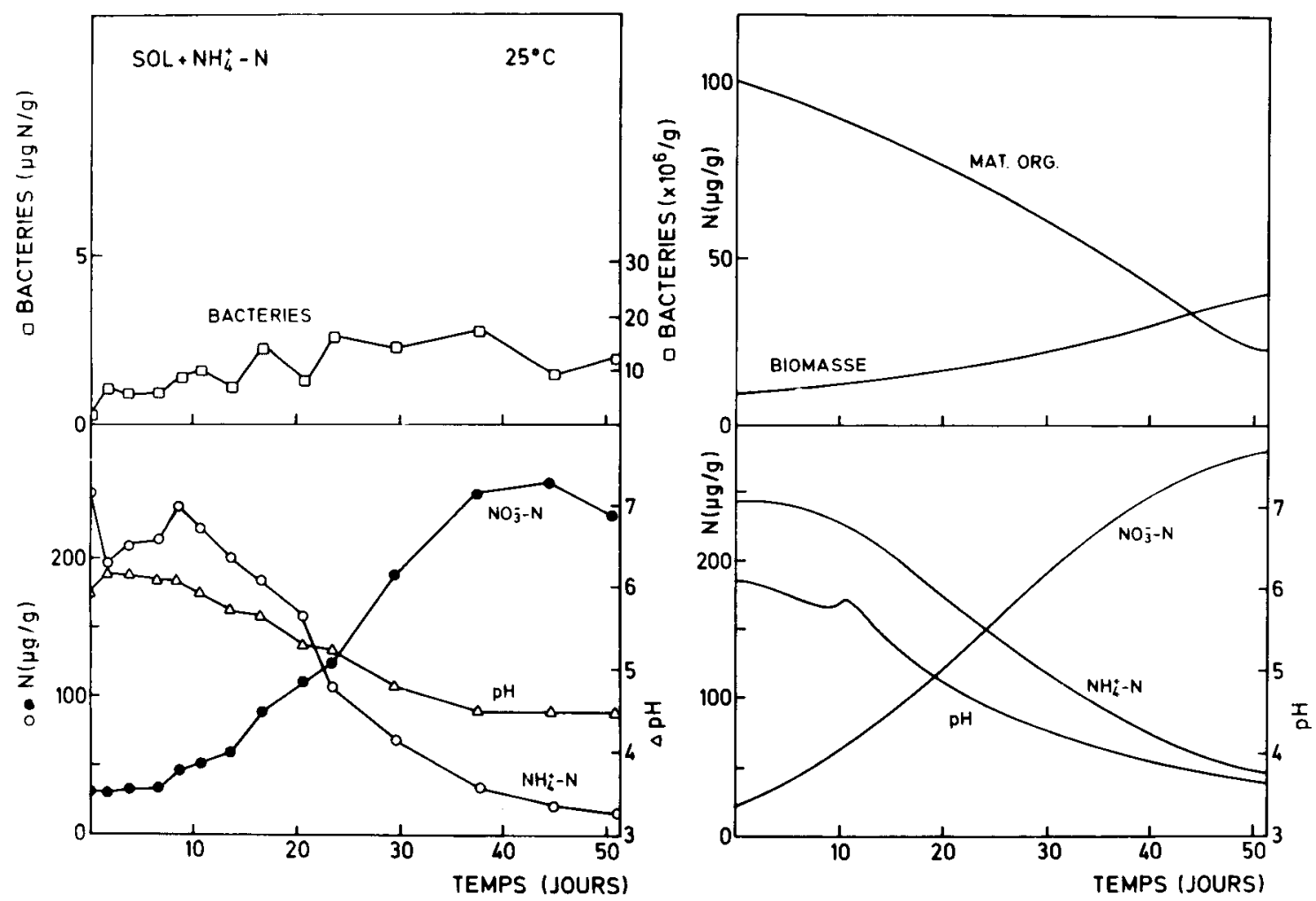

Figure 4

Le schéma expérimental est identique à celui de la figure 2, mais l'addition d'azote au sol ne comporte que 225 p.p.m. d'azote minéral sous forme de sulfate d'ammonium.

Same experimental procedure as in fig. 2 but with 225 p.p.m. mineral nitrogen added using ammonium sulfate. 


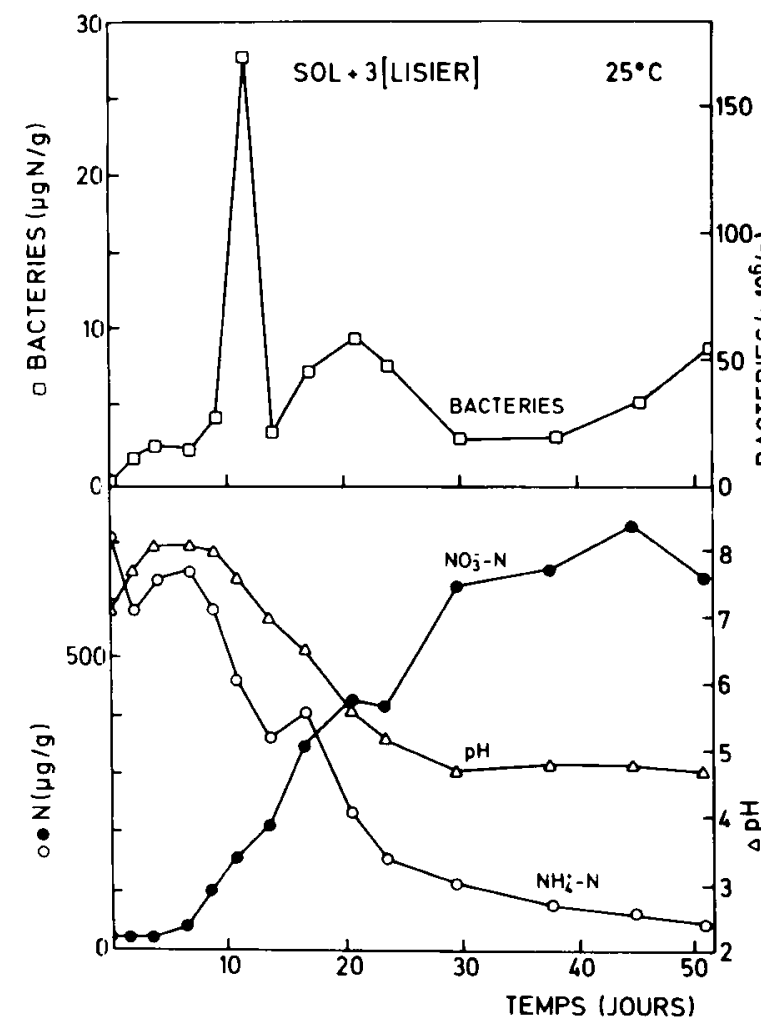

Figure 5

Le schéma expérimental est identique à celui de la figure 2 , mais la quantité d'azote organique et minéral ajoutée sous forme de lisier est le triple de celle de la figure 3.

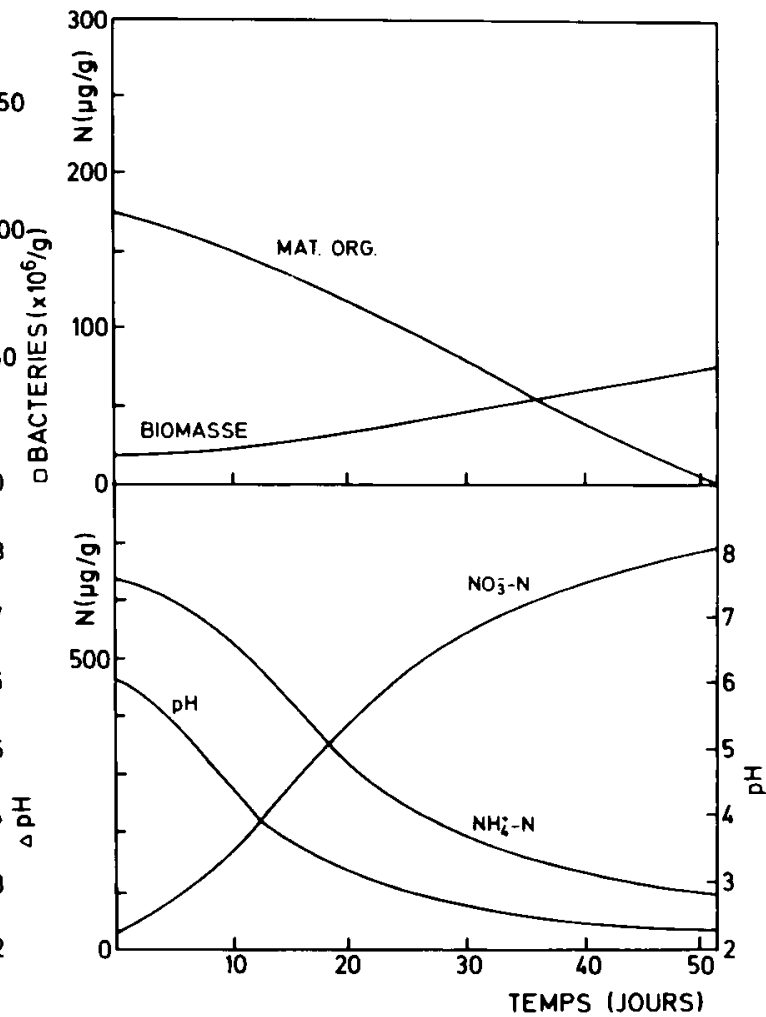

Same experimental procedure as in fig. 2 but with livestock effluent added at three times the rate of fig. 3 .
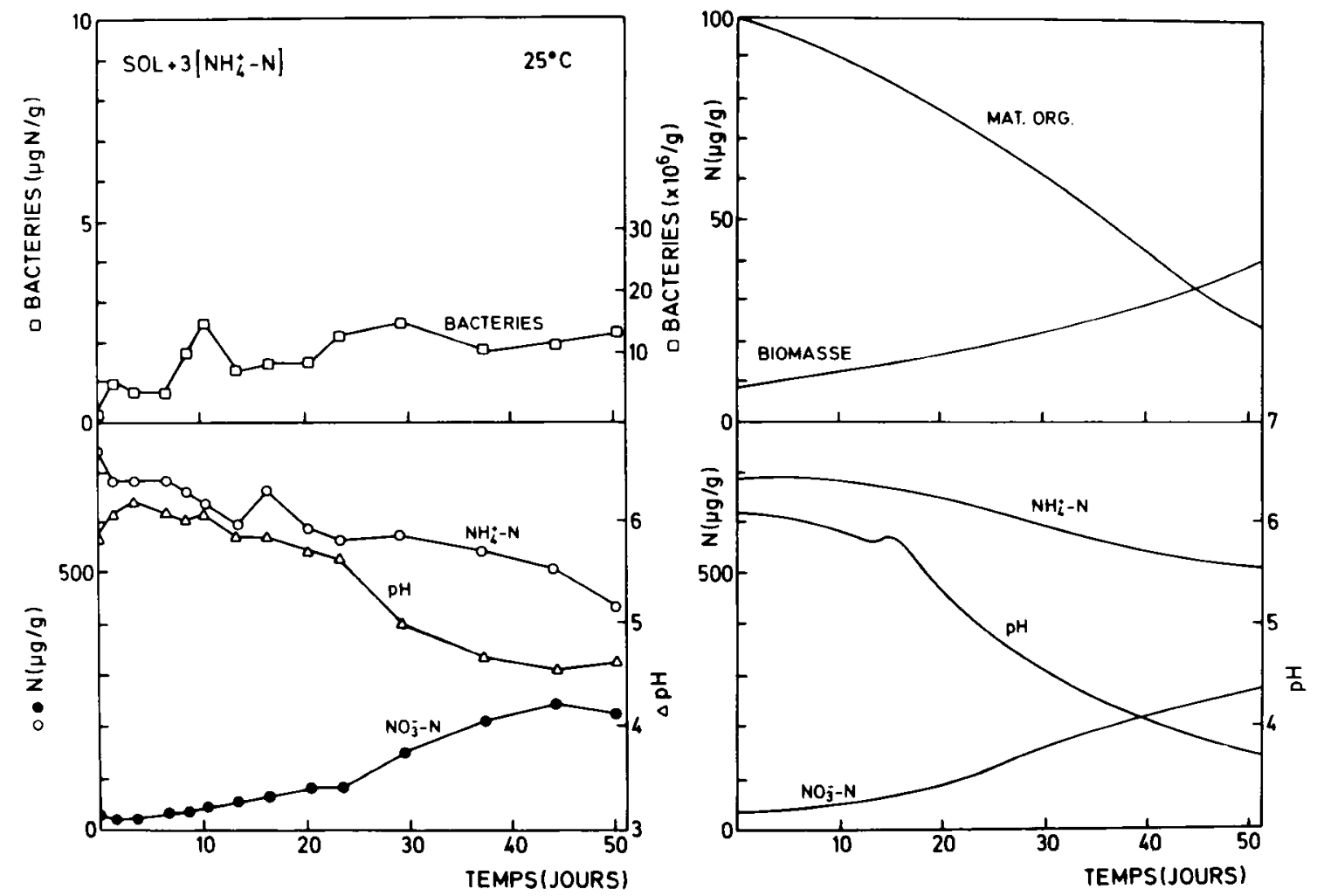

Figure 6

Le schéma expérimental est identique à celui de la figure 2, mais l'addition d'azote ne comporte que de l'azote ammoniacal à une dose triple de celle de la figure 4.

Same experimental procedure as in fig. 2 but with ammonium sulfate added at three times the rate of fig. 4 . 
TABLEAU 3

Paramètres à $30^{\circ} \mathrm{C}$ pour les simulations à différentes températures avec leur énergie apparente d'activation.

Parameters at $30^{\circ} \mathrm{C}$ for simulation at different temperatures.

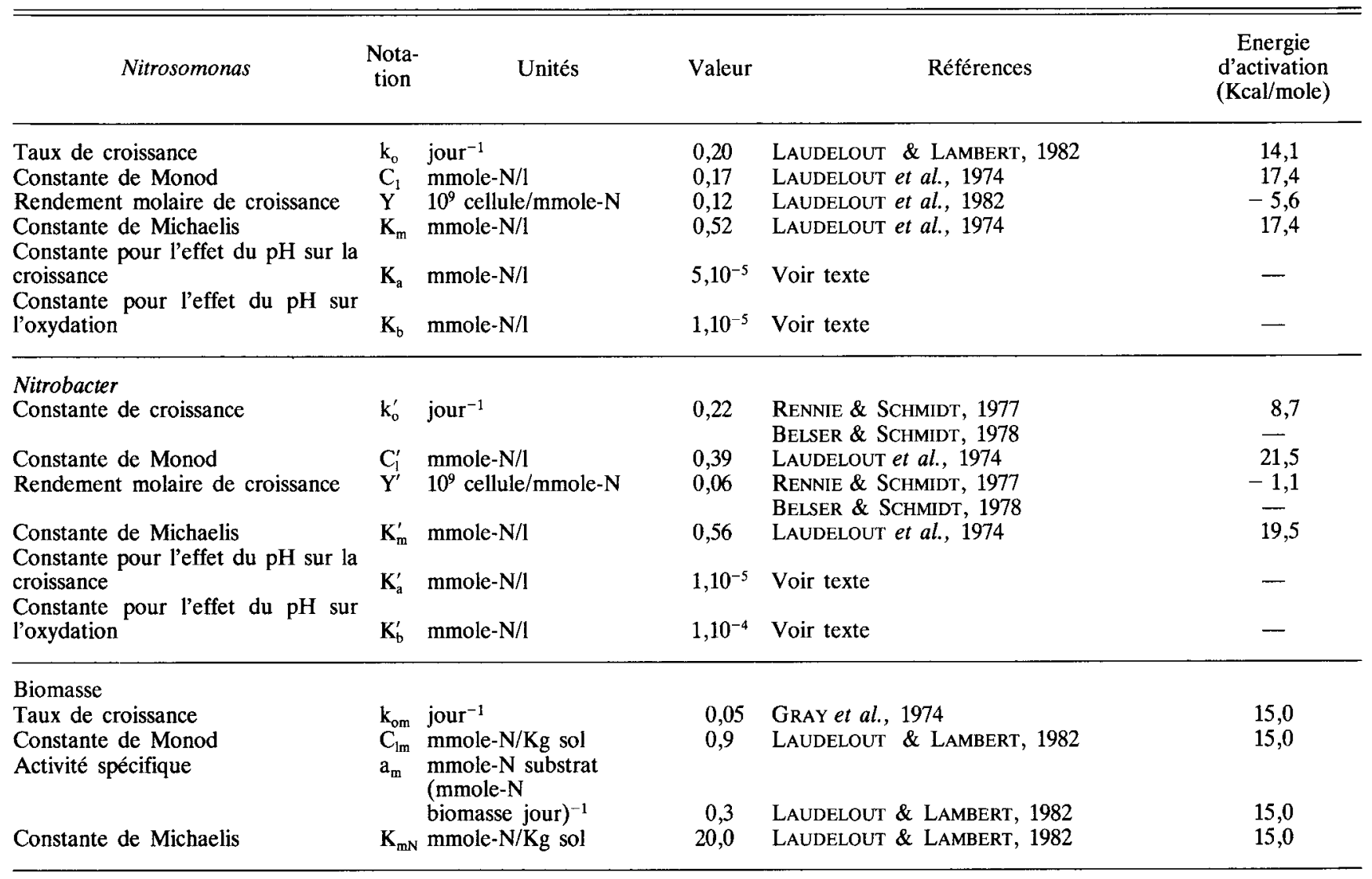

expérimentales et simulées lorsque les paramètres proviennent d'expériences indépendantes.

En outre, certains aspects propres à l'expérience décrite excluent une superposition parfaite et limitent l'accord aux aspects semi-quantitatifs. C'est ainsi que nous avons admis, pour la biomasse, une valeur de 1 à 10 pour le rapport entre le nombre de bactéries viables déterminé par numération sur milieu gélosé et la biomasse microbienne totale; ce rapport nous était suggéré par les numérations microscopiques directes et n'est donc pas entièrement arbitraire. En effet, le choix de l'ordre de grandeur pour le rapport entre cellules totales et cellules viables est imposé par les mesures de vitesse de dégagement du $\mathrm{CO}_{2}$ (reportée au tableau 4) lorsque la phase stationnaire est atteinte. On voit que le nombre moyen de bactéries viables par $\mathrm{g}$ de sol est de $19,4 \times 10^{6}$ correspondant à une vitesse de dégagement du $\mathrm{CO}_{2}$ de $0,9 \mu$ mole par jour. Si l'on admet une valeur de $2,3 \times 10^{-15}$ moles de $\mathrm{CO}_{2}$ par jour et par cellule, citée par ClARK (1967), pour la respiration du sol rapportée aux germes totaux, on calcule une valeur de $4 \times 10^{8}$ cellules par $g$ de sol soit 20 fois la valeur trouvée. Le choix d'un ordre de grandeur semble donc raisonnable.

- On voit que, compte tenu de ce changement d'échelle, la biomasse microbienne augmente au cours du temps d'une façon comparable à ce qui est observé expérimentalement sans toutefois les accidents que montrent les courbes expérimentales.

- En ce qui concerne les cinétiques de disparition de l'azote ammoniacal ou d'apparition du nitrate, leur similitude avec les courbes expérimentales est suffisante, compte tenu des irrégularités inévitables dues au mode d'échantil- lonnage pendant l'incubation que nous venons de mentionner.

- Il faut noter que le $p H$ calculé tombe nettement plus bas que ne le fait la valeur expérimentale. Ceci résulte très probablement du fait que le pouvoir tampon du sol tel qu'il a été mesuré sous-estime le pouvoir tampon réel du sol. Cette différence peut résulter du mode d'addition instantané de l'acide minéral utilisé pendant l'établissement de la courbe tampon, de la non-linéarité de la relation du $\mathrm{pH}$ en fonction du taux de dilution pour les fortes teneurs en ions $\mathrm{H}^{+}$, du mode d'acidification progressif correspondant à l'oxydation de l'ammonium et de la compensation de cette acidité par des facteurs biologiques.

- Nous avons procédé, d'autre part, à la mesure du dégagement de $\mathrm{CO}_{2}$ par du sol contenant des doses nulle, simple et triple de lisier dans les mêmes proportions que précédemment, la dose simple étant la même que dans les expériences précédentes.

Les résultats de cette expérience sont illustrés à la figure 7 où l'on voit que les courbes de production de $\mathrm{CO}_{2}$ se caractérisent par une partie linéaire dont les pentes, reportées au tableau 4 , ne diffèrent pas significativement et valent en moyenne $0,9 \mu$ mole $\mathrm{CO}_{2} / \mathrm{g}$ sol/jour, une valeur tout à fait similaire à ce qu'il est d'usage d'observer dans les sols mis en incubation dans les conditions utilisées. Cette phase linéaire de production de $\mathrm{CO}_{2}$ à un rythme constant est précédée d'une phase transitoire d'une dizaine de jours pendant laquelle le $\mathrm{CO}_{2}$ est dégagé à un rythme variable. L'importance de cette phase transitoire peut être estimée en extrapolant au terme $\mathrm{O}$ la partie linéaire des courbes de dégagement de $\mathrm{CO}_{2}$. 


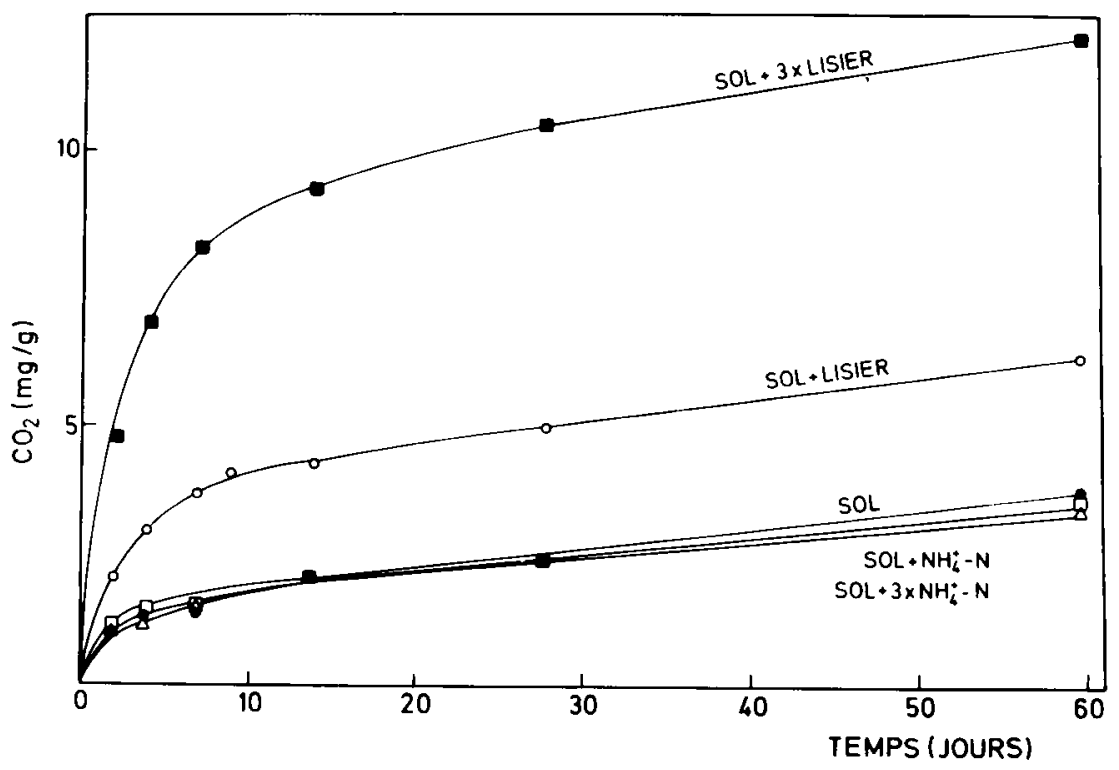

Figure 7

Evolution de la quantité de $\mathrm{CO}_{2}$ dégagé par le sol sous les divers traitements décrits précédemment.

Evolution of $\mathrm{CO}_{2}$ from control and treated soil-samples during 2 months of incubation.

TABLEAU 4

Vitesse de dégagement du $\mathrm{CO}_{2} \grave{a} 25^{\circ} \mathrm{C}$ pendant la période stationnaire entre 10 et $50 \mathrm{j}$ (fig. 7) comparée aux nombres moyens de bactéries viables observées pendant cette période.

Evolution of $\mathrm{CO}_{2}$ during the stationary period between the 10th and 50th days, with viable bacterial numbers and their ratios.

\begin{tabular}{|c|c|c|c|}
\hline Echantillon & $\begin{array}{l}\text { Vitesse de dégagement } \\
\mu \mathrm{mole} \cdot \text { jour } \\
-1 \cdot \mathrm{g}^{-1}\end{array}$ & $\begin{array}{c}\text { Nombre de } \\
\text { bactéries viables } \\
\left(\text { millions } \cdot g^{-1}\right)\end{array}$ & 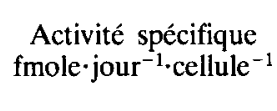 \\
\hline $\mathrm{S}(\mathrm{Sol})$ & .8 & 12 & 66 \\
\hline $\mathrm{N}\left(\mathrm{Sol}+\left(\mathrm{NH}_{4}\right)_{2} \mathrm{SO}_{4}\right)$ & $\cdot 7$ & 11 & 64 \\
\hline $3 \mathrm{~N}\left(\mathrm{Sol}+3 \times\left(\mathrm{NH}_{4}\right)_{2} \mathrm{SO}_{4}\right)$ & $\cdot 7$ & 12 & 58 \\
\hline $\mathrm{L}($ Sol + lisier $)$ & .9 & 26 & 35 \\
\hline $3 \mathrm{~L}(\mathrm{Sol}+3$ lisiers $)$ & $1 \cdot 4$ & 36 & 39 \\
\hline
\end{tabular}

Les valeurs des ordonnées à l'origine (corrigées pour le dégagement du $\mathrm{CO}_{2}$ par le sol témoin) pour les doses simple et triple de lisier sont dans le rapport 3,25/1 au lieu de 3/1. En ramenant les quantités de $\mathrm{CO}_{2}$ produites par $\mathrm{g}$ de matière sèche de lisier contenant en moyenne $74 \mathrm{p} .100$ de matière organique à 58 p. 100 de carbone (LECOMTE et al., 1979), on trouve que $69 \mathrm{p}$. 100 pour l'échantillon $\mathrm{L}$ et 79 p. 100 pour l'échantillon 3L de la matière organique du lisier, sont minéralisés après $50 \mathrm{j}$ d'incubation dans le sol.

- En ce qui concerne l'azote organique minéralisable, l'utilisation du modèle mathématique montre que 50 p.p.m. d'azote minéralisable auraient été apportées par le lisier dans le cas de la dose simple et 75 dans le cas de la dose triple. La proportionnalité est beaucoup moins satisfaisante que dans le cas de la minéralisation du carbone.

L'apport d'azote organique par le lisier correspondait à $2,15 \mathrm{mg}$ de matière sèche par $\mathrm{g}$ de sol soit, suivant les valeurs présentées au tableau 1, environ 100 p.p.m. d'azote organique. Le calcul de la teneur en azote organique à partir de l'ajustement du modèle permet donc de calculer un coefficient de minéralisation de l'azote organique de 50 p. 100 pour la dose simple de lisier et de 25 p. 100 pour la dose triple ; la première valeur est proche de la valeur de 42 p. 100 calculée à partir de la différence entre la quantité nette de nitrate produite par l'échantillon à partir du lisier ajouté pendant la période d'incubation. Par contre, l'apport de la dose triple de lisier a probablement conduit à des phénomènes d'anaérobiose locale et de dénitrification.

- L'effet de la température sur la nitrification de l'azote ammoniacal du lisier et sur la minéralisation de son azote organique peut être calculé si l'on connait les caractéristiques de température des paramètres du tableau 3.

Si certaines de ces caractéristiques sont relativement bien connues, il n'en va pas de même pour les paramètres relatifs à la croissance de la biomasse microbienne du sol et à son activité pour la minéralisation de l'azote organique. Nous avons utilisé la valeur "standard" de $15 \mathrm{kcal}$ pour les caractéristiques de températures inconnues.

Cette valeur de $15 \mathrm{kcal}$ correspond très exactement à ce qui peut être calculé à partir des expériences faites en parallèle par JENKINSON \& AYANABA (1977) au Nigéria et en Angleterre. Ces auteurs ont trouvé un facteur de 4 pour le rapport des vitesses de minéralisation à des températures moyennes annuelles différant de $17^{\circ} \mathrm{C}$. Une valeur voisine peut être calculée à partir des données de KöPF (1953).

Les expériences de laboratoire de LAUDELOUT \& MEYER (1951) conduisent à une même valeur pour des sols de texture moyenne. 

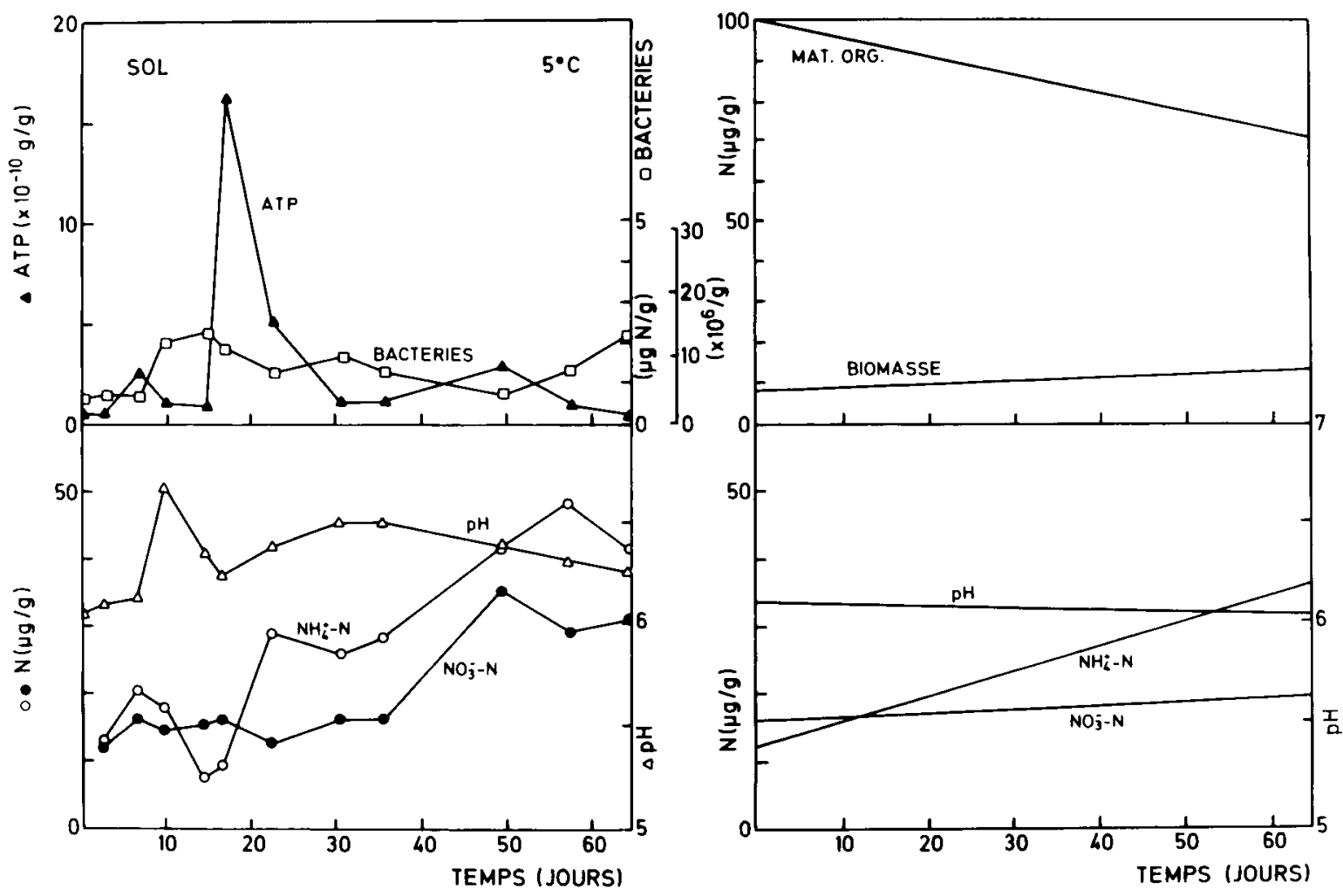

Figure 8

Evolution de la biomasse du sol témoin mesurée soit par le nombre de bactéries viables soit par la teneur en ATP, du pH et des teneurs en azote minéral à $5^{\circ} \mathrm{C}$. A droite, les courbes de simulation pour les paramètres et les caractéristiques de température du tableau 3.

Biomass recorded as number of viable cells or as ATP content, mineral nitrogen content and pH of soil samples (control) at $5{ }^{\circ} \mathrm{C}$. At right, simulation curves computed with the parameters from table 3.
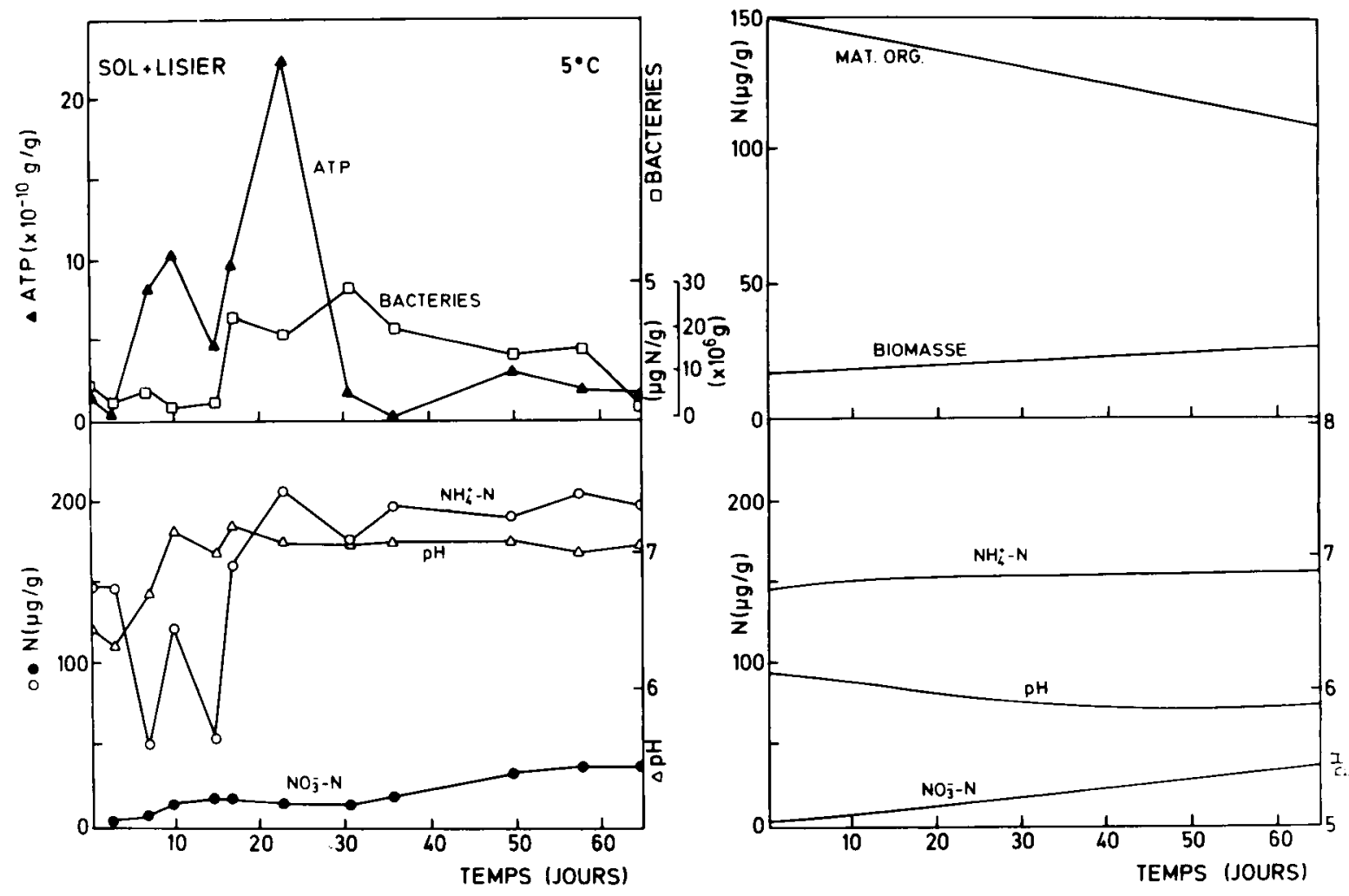

Figure 9

Idem figure 8, mais une dose simple de lisier a été ajoutée au sol.

Similar to fig. 8 but with soil samples treated with the lowest rate of pig slurry as in fig. 3. 
Les observations et les simulations pour les essais à $30^{\circ} \mathrm{C}$ et $13{ }^{\circ} \mathrm{C}$ diffèrent peu de celles à $25^{\circ} \mathrm{C}$ et ne sont pas représentées ici.

Les figures 8 et 9 présentent les valeurs calculées et expérimentales à $5^{\circ} \mathrm{C}$ et montrent la nécessité de disposer de données quantitatives plus précises sur les caractéristiques de température de la biomasse microbienne. Comme un modèle mathématique ne représente jamais qu'une simplification de la réalité, il est vraisemblable que l'allure des courbes de biomasse bactérienne présente un maximum de la population viable après $15 \mathrm{j}$ et qu'un maximum de la concentration en ATP traduise l'existence de phénomènes caractéristiques du développement bactérien à basse température dans le sol et qui ne sont pas pris en compte par le modèle mathématique.

\section{CONCLUSION}

Le travail dont les résultats ont été présentés ci-dessus ne se rapporte qu'à un seul type de lisier et à un seul échantillon d'ure matière dont il est inutile de souligner la variabilité.

Il nous a semblé intéressant d'en faire connaître la démarche qui permettrait une économie considérable de temps lors de l'évaluation de la capacité de la matière organique du lisier de contribuer à la nutrition azotée de la plante. Il est clair que les déterminations expérimentales qui ont été effectuées auraient pu être grandement simplifiées tant en ce qui concerne leur nombre que leur durée. On aurait pu, par exemple, lors d'une expérience de minéralisation, se limiter à l'observation des cinétiques de disparition de l'ammonium et d'apparition du nitrate pendant 2 semaines pour arriver à prédire de façon satisfaisante la quantité d'azote organique minéralisable en utilisant le modèle. Le très grand nombre de paramètres et de conditions initiales qui figurent dans ce modèle ne semble pas être une objection majeure à son emploi. En effet, en se basant sur les résultats de plus de 350 simulations, bon nombre des paramètres qui $\mathrm{y}$ figurent semblent avoir un domaine d'utilisation assez large et, d'autre part, les conditions initiales de détermination malaisée (biomasse hétérotrophe ou nitrifiante) ne semblent pas influer considérablement sur l'allure générale de la cinétique dans les limites des valeurs plausibles pour un sol donné.

Le tableau $5 \mathrm{~b}$ montre l'accord interne des valeurs concernant la quantité de matière organique minéralisable mesurée, soit par la cinétique de dégagement du $\mathrm{CO}_{2}$, soit par

\section{TABLEAU 5}

5a : Rapport $\mathrm{C} / \mathrm{N}$ des échantillons avant l'incubation. $C / N$ ratio of samples before incubation.

\begin{tabular}{cccc}
\hline Echantillon & $\begin{array}{c}\mathrm{C} \text { organique }(*) \\
(\boldsymbol{\%})\end{array}$ & $\begin{array}{c}\mathrm{N} \text { total }\left({ }^{* *}\right) \\
(\mathbf{\%})\end{array}$ & $\begin{array}{c}\mathrm{C} / \mathrm{N} \\
(\mathrm{g} / \mathrm{g})\end{array}$ \\
\hline $\mathrm{S}$ & 1,18 & 0,17 & 6,95 \\
$\mathrm{~N}$ & 1,18 & 0,19 & 6,21 \\
3N & 1,18 & 0,24 & 4,96 \\
$\mathrm{~L}$ & 1,27 & 0,20 & 6,35 \\
3L & 1,46 & 0,27 & 5,41 \\
\hline
\end{tabular}

$\left(^{*}\right)$ Méthode de WalkLEY-BLACK avec $\mathrm{f}=1,12$.

$\left({ }^{* *}\right)$ Méthode de KJELDAHL.

5b: Rapport $C / N$ pour les fractions minéralisables après $50 j$ d'incubation à $25^{\circ} \mathrm{C}$.

$\mathrm{C} / \mathrm{N}$ ratio of samples after 50 days incubation at $25^{\circ} \mathrm{C}$.

\begin{tabular}{cccr}
\hline \hline Echantillon & $\begin{array}{c}\mathrm{CO}_{2} \text { dégagé }\left(^{*}\right) \\
(\mu \mathrm{gC} / \mathrm{g} \text { sol })\end{array}$ & $\begin{array}{c}\mathrm{N} \text { organique } \\
\text { utilisé }(* *) \\
(\mu \mathrm{g} / \mathrm{g} \text { sol })\end{array}$ & $\begin{array}{r}\mathrm{C} / \mathrm{N} \\
(\mathrm{g} / \mathrm{g})\end{array}$ \\
\hline $\mathrm{S}$ & 839 & 75 & 11,2 \\
$\mathrm{~N}$ & 806 & 75 & 10,7 \\
3N & 778 & 75 & 10,4 \\
$\mathrm{~L}$ & 1481 & 150 & 9,8 \\
$3 \mathrm{~L}$ & 3046 & 175 & 17,4 \\
\hline
\end{tabular}

${ }^{*}$ ) Le $\mathrm{CO}_{2}$ dégagé est mesuré ;

$\left({ }^{* *}\right)$ l'azote organique minéralisable est calculé d'après les cinétiques d'ammonification et de nitrification.

l'utilisation du modèle sur la cinétique d'ammonification et de nitrification pendant 50 jours.

Les rapports $\mathrm{C} / \mathrm{N}$ de la matière organique du sol et $\mathrm{du}$ lisier, qui sont voisins de 6 au départ (tabl. $5 a$ ) et de 10 après $50 \mathrm{j}$ d'incubation, se reflètent dans les quantités de matière organique minéralisée, à l'exception du traitement avec une dose triple de lisier. Ce traitement représente $315 \mathrm{~m}^{3} / \mathrm{ha}$, ce qui risque évidemment de perturber la cinétique de minéralisation et de nitrification par l'induction de conditions anaérobies.

Reçu le 21 octobre 1982 Accepté le 17 août 1983.

\section{ANNEXE}

Les résultats des simulations proviennent de la résolution du système d'équations différentielles qui tient compte des phénomènes suivants (pour les notations, voir tabl. 3 ) :

a) Croissance de la biomasse $\mathrm{m}$ par immobilisation de la matière organique $\mathbf{N}$ :

$$
\frac{\mathrm{dm}}{\mathrm{dt}}=\frac{\mathrm{k}_{0 \mathrm{~m}} \cdot \mathrm{m} \cdot \mathrm{N}}{\mathrm{C}_{1 \mathrm{~m}}+\mathrm{N}}
$$

b) Minéralisation de la matière organique $\mathrm{N}$ par ammonification et immobilisation :

$$
\frac{\mathrm{dN}}{\mathrm{dt}}=-\frac{\mathrm{a}_{\mathrm{m}} \cdot \mathrm{m} \cdot \mathrm{N}}{\mathrm{K}_{\mathrm{mN}}+\mathrm{N}}-\frac{\mathrm{dm}}{\mathrm{dt}} .
$$

c) Croissance de Nitrosomonas n par oxydation de l'azote ammoniacal C:

$$
\begin{aligned}
& \frac{d n}{d t}=\frac{k_{0} \cdot n \cdot C}{\left(C_{1}+C\right)} \cdot f_{a} \\
& f_{a}=\frac{1+\{H\}_{b} / K_{a}}{1+\{H\} / K_{a}} .
\end{aligned}
$$$$
\text { où }
$$

d) Libération des ions $\mathrm{H}^{+}$suite à l'oxydation de l'azote ammoniacal C:

$$
\frac{d H}{d t}=\frac{2 k_{0} \cdot n \cdot C}{Y\left(K_{m}+C\right)} \cdot f_{b}
$$


où

$$
\mathrm{f}_{\mathbf{b}}=\frac{1+\{\mathrm{H}\}_{\mathrm{b}} / \mathrm{K}_{\mathbf{b}}}{1+\{\mathbf{H}\} / \mathrm{K}_{\mathbf{b}}}
$$

e) Production de l'azote ammoniacal C par ammonification et son oxydation par Nitrosomonas:

$$
\frac{d c}{d t}=\frac{a_{m} \cdot m \cdot N}{K_{m N}+N}-\frac{d H}{2 d t} .
$$

f) Croissance de Nitrobacter $n^{\prime}$ par oxydation de l'azote nitreux $C^{\prime}$ :$$
\text { où }
$$

$$
\frac{\mathrm{dn} n^{\prime}}{\mathrm{dt}}=\frac{\mathrm{k}_{0}^{\prime} \cdot \mathrm{n}^{\prime} \cdot \mathrm{C}^{\prime}}{\mathrm{C}_{1}^{\prime}+\mathrm{C}^{\prime}} \cdot \mathrm{f}_{\mathrm{a}}^{\prime}
$$

$$
\mathrm{f}_{\mathrm{a}}^{\prime}=\frac{1+\{\mathrm{H}\}_{\mathrm{b}} / \mathrm{K}_{\mathrm{a}}^{\prime}}{1+\{\mathrm{H}\} / \mathrm{K}_{\mathrm{a}}^{\prime}}
$$

g) Production de nitrate par oxydation de l'azote nitreux C' par Nitrobacter $n^{\prime}$ :

$$
\frac{\mathrm{d}\left\{\mathrm{NO}_{3}\right\}}{\mathrm{dt}}=\frac{\mathrm{k}_{0}^{\prime} \cdot \mathrm{n}^{\prime} \cdot \mathrm{C}^{\prime}}{\mathrm{Y}^{\prime}\left(\mathrm{K}_{\mathrm{m}}^{\prime}+\mathrm{C}^{\prime}\right)} \cdot \mathrm{f}_{\mathrm{b}}^{\prime}
$$

où

$$
\mathrm{f}_{\mathbf{b}}^{\prime}=\frac{1+\{\mathrm{H}\}_{\mathrm{b}} / \mathbf{K}_{\mathrm{b}}^{\prime}}{1+\{\mathrm{H}\} \cdot \mathrm{C}^{\prime} / \mathbf{K}_{\mathrm{b}}^{\prime}}
$$

h) Production du nitrite $\mathbf{C}^{\prime}$ par Nitrosomonas et son oxydation par Nitrobacter:

$$
\frac{\mathrm{dC}}{\mathrm{dt}}=\frac{\mathrm{dH}}{2 \mathrm{dt}}-\frac{\mathrm{d}\left\{\mathrm{NO}_{3}\right\}}{\mathrm{dt}} .
$$

Les fonctions $f_{a}, f_{b}, f_{a}^{\prime}, f_{b}^{\prime}$ représentent l'effet du pH sur la croissance des bactéries nitrifiantes et leur pouvoir oxydatif et la constante $\{\mathrm{H}\}_{\mathrm{b}}$, la teneur en ions $\mathrm{H}^{+}$au $\mathrm{pH}(7,7)$ où les constantes $\mathrm{K}_{\mathrm{a}}, \mathrm{K}_{\mathrm{b}}, \mathrm{K}_{\mathrm{a}}^{\prime}, \mathrm{K}_{\mathrm{b}}^{\prime}$ sont déterminées.

Les ions $\mathrm{H}^{+}$produits par l'équation (d) interviennent indirectement dans ces fonctions à travers une relation empirique entre le pouvoir tampon du sol et la teneur en eau (fig. 1).

Nous avons utilisé l'algorithme Runge-Kutta-Merson du $4^{\mathrm{e}}$ ordre à pas variable pour l'intégration du système d'équations. Le recouvrement du bilan d'azote initial s'avère excellent $(100 \pm 0,1 \mathrm{p} .100)$ après $50 \mathrm{j}$ et le système reste toujours stable.

\section{RÉFÉRENCES BIBLIOGRAPHIQUES}

Belser L. W., Schmidt E. L., 1978. Nitrification in soils. In Microbiology, Schlessinger D. ed., Am. Soc. Microbiol., Washington, 348-351.

Clark F. E., 1965. Agar-plate method for total microbial count in Methods of Soil Analysis, Black C. A. et al. ed., 2, Am. Soc. Agron., Madison, 1460-1466.

Clark F. E., 1967. Bacteria in soil. In Soil Biology, p. 15-49, Burges A. and Ray F. ed., Academic Press, London.

Cooper J. E., 1975. Nitrification in soils incubated with pig slurry. Soil Biol. Biochem., 7, 119-124.

Eiland F., 1981. Organic manure in relation to microbiological activity in soil. In Agricultural yield potentials in continental climates Proc. 16th Colloq. Int. Potash, Inst. Warsaw, Poland. Int. Potash Inst., Bern, Ed.

Gray T. R. G., Hisset R., Duxbury, 1974. Bacterial populations of litter and soil in a deciduous woodland II. Numbers, biomass and growth rates. Rev. Ecol. Biol. Sol, 11, 15-26.

Hobson P. N., 1969. Rumen bacteria. In Methods in Microbiology, Norris J. R. \& Ribbons D. W. ed., Academic Press, London, 38, 133-149.

Jenkinson D. S., Ayanaba A., 1977. Decomposition of carbon-14labeled plant material under tropical conditions. Soil Sci. Am. J., 41, 912-915.

Jones P. C. T., Mollison J. E., 1948. A technique for the quantitative estimation of soil micro-organisms. J. Gen. Microbiol., 2, 5469.

Köpf H., 1953. Die Temperatur-Zeit Abhängigkeit der Bodenatmung. Z. Pflanzenernähr. Düng. u. Bodenk., 61, $29-48$.

Laudelout H., Germain L., Chabalier P. F., Chiang C. N., 1977. Computer simulation of loss of fertilizer nitrogen through chemical decomposition of nitrite. J. Soil Sci., 28, 329-339.

Laudelout H., Lambert R., 1982. Variation saisonnière de la population microbienne du sol. II. Influence sur la minéralisation de l'azote du sol. Rev. Ecol. Biol. Sol, 19, 1-15.
Laudelout H., Lambert R., Fripiat J. L., Pham M. L., 1974. Effet de la température sur la vitesse d'oxydation de l'ammonium en nitrate par des cultures de nitrifiants. Ann. Microbiol. (Institut Pasteur), 125B, 75-84.

Laudelout H., Lambert R., Pham M. L., 1976. Influence du pH et de la pression partielle d'oxygène sur la nitrification. Ann. Microbiol. (Inst. Pasteur), 127A, 367-382.

Laudelout H., Meyer J., 1951. Temperature characteristics of the microflora of Central African soils. Nature, London, 168, 791.

Lecomte R., Couvreur L., Crohain A., Destain J. P., Droeven G., Frankinet M., Guiot J., Raimond Y., Rixhon L., 1979. The influence of agronomic application of slurry on the yield and composition of arable crops and grassland and on change in soil properties. In Effluents from Livestock, Gasser J. K. R. ed., Applied Science Publishers. London, 139-180.

Lumac Systems, 1978. Lumac methods for microbial ATP and quantitation of microbial cells. Application Bulletin 511, Basel, $20 \mathrm{p}$.

Martin J. P., 1950. Use of acid, rose bengal and streptomycin in the plate method for estimating soil fungi. Soil Sci., 69, 215.

Rennie R. J., Schmidt E. L., 1977. Autoecological and kinetic analysis of competition between Nitrobacter strains in soil. In Soil organisms as components of ecosystems, John V. \& Persson T. ed., Proc. 6 th Int. Soil Zool Colloq. Ecol. Bull. (Stockholm), 25, 431441.

Smith S. J., Mathers A. C., Stewart B. A., 1980. Distribution of nitrogen forms in soil receiving cattle feedlot waste. J. Environ. Qual., 9, 215-218.

Thornton H. G., 1922. On the development of a standardized agar medium for counting soil bacteria, with special regard to the repression of spreading colonies. Ann. appl. Biol., 9, 241-274. 